\title{
Absolute Summability Factors Related to the Summability Method $\left|\bar{N}, p_{n}, \theta\right|(\mu)$
}

\section{Fadime GÖKÇE ${ }^{1}$}

\begin{abstract}
By $(A, B)$, we denote the set of all sequences $\epsilon$ such that $\sum a_{n} \epsilon_{n}$ is summable $B$ whenever $\sum a_{n}$ is summable $A$ where $A$ and $B$ are two summability methods. In this study, applying the main theorems in (Gökçe and Sarıöl, 2018) to summability factors, we characterize the sets $\left(\left|\bar{N}, p_{n}, \theta\right|(\mu),\left|\bar{N}, q_{n}\right|\right)$ and $\left(\left|\bar{N}, p_{n}, \theta\right|(\mu),\left|\bar{N}, q_{n}, \psi\right|(\lambda)\right)$. Also, in the special case, we get some well-known results.
\end{abstract}

Keywords: Absolute weighted summability, summability factors, matrix transformations, sequence spaces.

\section{$\left|\overline{\boldsymbol{N}}, \boldsymbol{p}_{\boldsymbol{n}}, \boldsymbol{\theta}\right|(\boldsymbol{\mu})$ Toplanabilme Metodu ile İlgili Mutlak Toplanabilme Çarpanları}

ÖZET: $A$ ve $B$ iki toplanabilme metodu olmak üzere $\sum a_{n}, A$ toplanabilir iken $\sum a_{n} \epsilon_{n}, \quad B$ toplanabilir olacak şekildeki bütün $\epsilon$ dizilerinin kümesi $(A, B)$ ile gösterilir ve $\epsilon$ dizisine toplanabilme çarpanı adı verilir. Bu çalışmada, (Gökçe ve Sarıgöl, 2018) tarafından verilen teoremler yardımiyla $\left(\left|\bar{N}, p_{n}, \theta\right|(\mu),\left|\bar{N}, q_{n}\right|\right)$ ve $\left(\left|\bar{N}, p_{n}, \theta\right|(\mu),\left|\bar{N}, q_{n}, \varphi\right|(\lambda)\right)$ toplanabilme çarpanları kümeleri karakterize edilmiştir. Ayrıca özel durumlarda, bilinen bazı sonuçlar elde edilmiştir.

Anahtar Kelimeler: Mutlak ağırlıklı ortalama toplanabilme, toplanabilme çarpanı, matris dönüşümleri, dizi uzayları.

\footnotetext{
${ }^{1}$ Fadime GÖKÇE (Orcid ID: 0000-0003-1819-3317), Pamukkale Üniversitesi Fen Edebiyat Fakültesi, Matematik Bölümü, Denizli, , Türkiye

*Sorumlu Yazar / Corresponding Author: Fadime GÖKÇE, e-mail: fgokce@pau.edu.tr
} 


\section{INTRODUCTION}

Let $\sum a_{v}$ be a given infinite series with partial sum $s_{n}, \theta=\left(\theta_{n}\right)$ be any sequence of positive real numbers and $\mu=\left(\mu_{n}\right)$ be any bounded sequence of positive real numbers. If

$$
\sum_{n=1}^{\infty} \theta_{n}^{\mu_{n-1}}\left|A_{n}(s)-A_{n-1}(s)\right|^{\mu_{n}}<\infty
$$

where

$$
A_{n}(s)=\sum_{v=0}^{\infty} a_{n v} s_{v}
$$

then the series $\sum a_{v}$ is said to be summable $|A, \theta|(\mu)$ (Gökçe and Sarıöl, 2018).

Let $\left(p_{n}\right)$ be a sequence of nonnegative numbers with $P_{n}=p_{0}+p_{1}+\cdots+p_{n} \rightarrow \infty$ as $n \rightarrow$ $\infty\left(P_{-1}=p_{-1}=0\right)$. If we take the weighted mean matrix instead of $A$, the summability $|A, \theta|(\mu)$ is reduced to the summability $\left|\bar{N}, p_{n}, \theta\right|(\mu)$, and also the space of all series summable by $\left|\bar{N}, p_{n}, \theta\right|(\mu)$ is defined as follows (Gökçe and Sarıöl, 2018)

$$
\left|\bar{N}_{p}^{\theta}\right|(\mu)=\left\{a=\left(a_{v}\right): \sum_{n=1}^{\infty} \theta_{n}^{\mu_{n-1}}\left|\frac{p_{n}}{P_{n} P_{n-1}} \sum_{v=1}^{n} P_{v-1} a_{v}\right|^{\mu_{n}}<\infty\right\} .
$$

One gives the weighted mean matrix by

$$
a_{n v}=\left\{\begin{array}{cl}
p_{v} / P_{n}, & 0 \leq v \leq n \\
0, & v>n
\end{array}\right.
$$

The series-to-sequence transformations corresponding to the summability $\left|\bar{N}, p_{n}, \theta\right|(\mu)$

$$
T_{0}=a_{0} \theta_{0}^{1 / \mu_{0}^{*}}, T_{n}=\theta_{n}^{1 / \mu_{n}^{*}} \frac{p_{n}}{P_{n} P_{n-1}} \sum_{v=1}^{n} P_{v-1} a_{v}, n \geq 1
$$

define the sequence $\left(T_{n}\right)$. Also, a few calculations show that its inverse transformation is as follows:

$$
a_{n}=\theta_{n}^{-1 / \mu_{n}^{*}} \frac{P_{n}}{p_{n}} T_{n}-\theta_{n-1}^{-1 / \mu_{n-1}^{*}} \frac{P_{n-2}}{p_{n-1}} T_{n-1}, n \geq 0
$$

Now, we assume that $0<\inf \mu_{n}<\infty$ and $\mu_{n}^{*}$ is conjugate of $\mu_{n}$, i.e., $1 / \mu_{n}^{*}+1 / \mu_{n}=1$ for $\mu_{n}>$ $0,1 / \mu_{n}^{*}=0$ for $\mu_{n}=1$ in the whole paper.

Note that the summability $\left|\bar{N}, p_{n}, \theta\right|(\mu)$ reduces to some well-known methods in special case of $\mu$ and $\theta$. For example, if we take $\mu_{n}=k$ for all $n \geq 0$, then we have the summability $\left|\bar{N}, p_{n}, \theta\right|_{k}$ (Sarıöl, 2011) and the summability $\left|\bar{N}, p_{n}\right|_{k}$ with $\theta_{n}=P_{n} / p_{n}$ (Orhan and Sarıgöl, 1993).

\section{MATERIALS AND METHODS}

Let $A$ and $B$ be two summability methods. If $\sum a_{n} \epsilon_{n}$ is summable $B$ whenever $\sum a_{n}$ is summable $A$, then it is said that $\epsilon$ is summability factor of type $(A, B)$, denoted by $\epsilon \in(A, B)$. In this paper, applying the main theorems in (Gökçe and Sarı̈öl, 2018) to summability factors, we characterize the sets $\left(\left|\bar{N}, p_{n}, \theta\right|(\mu),\left|\bar{N}, q_{n}\right|\right)$ and $\left(\left|\bar{N}, p_{n}, \theta\right|(\mu),\left|\bar{N}, q_{n}, \psi\right|(\lambda)\right)$ where $\left(\theta_{n}\right)$ and $\left(\psi_{n}\right)$ are sequences of positive numbers and $\left(\mu_{n}\right)$ and $\left(\lambda_{n}\right)$ are arbitrary bounded sequences of positive numbers. Also, in the special case, we get some well-known results.

Definition 2.1 Let $f$ and $g$ be any real valued functions defined on some unbounded subset of the positive real numbers. Then, $f(x)=O(g(x))$ if and only if there exists a positive real number $M$ and a real number $x_{0}$ such that $|f(x)| \leq M g(x)$ for all $x \geq x_{0}$. 
Lemma 2.2 Let $k \geq 1$ and $\left(p_{n}\right)$ be a sequence of positive numbers. If $P_{n}=p_{0}+p_{1}+\cdots+$ $p_{n} \rightarrow \infty$ as $n \rightarrow \infty\left(P_{-1}=p_{-1}=0\right)$, then

(Sarı̈öl, 2016).

$$
\frac{1}{k P_{v-1}^{k}} \leq \sum_{n=v}^{\infty} \frac{p_{n}}{P_{n} P_{n-1}^{k}} \leq \frac{1}{P_{v-1}^{k}}
$$

Theorem 2.3 Let $A=\left(a_{v}\right)$ be an infinite matrix of complex numbers and $\left(\theta_{n}\right)$ be a sequence of positive numbers. If $\mu=\left(\mu_{n}\right)$ is an arbitrary bounded sequence of positive numbers such that $\mu_{n}>1$ for all $n$, then $A \in\left(\left|\bar{N}_{p}^{\theta}\right|(\mu),\left|\bar{N}_{q}\right|\right)$ if and only if there exists an integer $M>1$ such that, for $n=0,1, \ldots$,

$$
\begin{gathered}
\sup _{m}\left|\frac{M^{-1} P_{m} a_{n m}}{\theta_{m}^{1 / \mu_{m}^{*}} p_{m}}\right|^{\mu_{m}^{*}}<\infty, \\
\sum_{v=0}^{\infty}\left|M^{-1} \hat{a}_{n v}\right|^{\mu_{v}^{*}}<\infty, \\
\sum_{v=0}^{\infty}\left(\sum_{n=1}^{\infty} \frac{M^{-1} q_{n}}{Q_{n} Q_{n-1}}\left|\sum_{j=1}^{n} Q_{j-1} \hat{a}_{j v}\right|\right)^{\mu_{v}^{*}}<\infty
\end{gathered}
$$

where

$$
\hat{a}_{n v}=\frac{P_{v}}{\theta_{v}^{1 / \mu_{v}^{*}} p_{v}}\left(a_{n v}-\frac{P_{v-1}}{P_{v}} a_{n, v+1}\right)
$$

(Gökçe and Sarıgöl, 2018).

Theorem 2.4 Let $A=\left(a_{n v}\right)$ be an infinite matrix of complex numbers, $\left(\theta_{n}\right)$ and $\left(\psi_{n}\right)$ be sequences of positive numbers. If $\mu=\left(\mu_{n}\right)$ and $\lambda=\left(\lambda_{n}\right)$ are any bounded sequences of positive numbers such that $\mu_{n} \leq 1$ and $\lambda_{n} \geq 1$ for all $n$, then, $A \in\left(\left|\bar{N}_{p}^{\theta}\right|(\mu),\left|\bar{N}_{q}^{\psi}\right|(\lambda)\right)$ if and only if there exists an integer $M>1$ such that, for $n=0,1, \ldots$,

$$
\begin{gathered}
\sup _{v}\left|\hat{a}_{n v}\right|^{\mu_{v}}<\infty, \\
\sup _{m}\left|\frac{P_{m} a_{n m}}{\theta_{m}^{1 / \mu_{m}^{*}} p_{m}}\right|<\infty,
\end{gathered}
$$

and

$$
\sup _{v} \sum_{n=1}^{\infty}\left|\frac{\psi_{n}^{1 / \lambda_{n}^{*}} q_{n} M^{-1 / \mu_{v}}}{Q_{n} Q_{n-1}} \sum_{j=1}^{n} Q_{j-1} \hat{a}_{j v}\right|^{\lambda_{n}}<\infty,
$$

(Gökçe and Sarıöl, 2018).

Lemma 2.5 Let $a, b \in \mathbb{C}, k \geq 0$ and $c_{k}=1$ for $k \leq 1, c_{k}=2^{k-1}$ for $k>1$. Then,

(Mitrinovic, 1970).

$$
|a+b|^{k} \leq c_{k}\left(|a|^{k}+|b|^{k}\right),
$$




\section{RESULTS AND DISCUSSION}

In this section, firstly we give main theorems and then, by making special chooses for $\psi, \theta, \mu$ and $\lambda$, we obtain certain well-known corollaries.

Theorem 3.1 Let $\left(\theta_{n}\right)$ be a sequence of positive numbers and $\left(\mu_{n}\right)$ be an arbitrary bounded sequence of positive numbers with $\mu_{n}>1$ for all $n$. Then, $\epsilon \in\left(\left|\bar{N}, p_{n}, \theta\right|(\mu),\left|\bar{N}, q_{n}\right|\right)$ if and only if

$$
\begin{gathered}
\sum_{v}^{\infty}\left(M^{-1} \frac{P_{v} q_{v}}{Q_{v} p_{v}} \theta_{v}^{-1 / \mu_{v}^{*}}\left|\epsilon_{v}\right|\right)^{\mu_{v}^{*}}<\infty \\
\sum_{v}^{\infty}\left(M^{-1} \theta_{v}^{-1 / \mu_{v}^{*}}\left|\frac{P_{v}}{p_{v}} \Delta \epsilon_{v}+\epsilon_{v+1}\right|\right)^{\mu_{v}^{*}}<\infty
\end{gathered}
$$

where $\Delta \epsilon_{v}=\epsilon_{v}-\epsilon_{v+1}$ for all $v \geq 0$.

Proof. Take the diagonal matrix $W$ instead of $A$ in Theorem 2.3. Then, (4) and (5) are directly satisfied. Also, using Lemma 2.2, we get

$$
\begin{gathered}
\sum_{v=0}^{\infty} \frac{M^{-1 / \mu_{v}^{*}}}{\theta_{v}}\left(\frac{q_{v} P_{v}}{Q_{v} p_{v}}\left|\epsilon_{v}\right|+\sum_{n=v+1}^{\infty} \frac{q_{n}}{Q_{n} Q_{n-1}}\left|\frac{P_{v}}{p_{v}}\left(Q_{v-1} \epsilon_{v}-\frac{P_{v-1}}{P_{v}} Q_{v} \epsilon_{v+1}\right)\right|\right)^{\mu_{v}^{*}} \\
=\sum_{v=0}^{\infty} \frac{M^{-1 / \mu_{v}^{*}}}{\theta_{v}}\left(\frac{q_{v} P_{v}}{Q_{v} p_{v}}\left|\epsilon_{v}\right|+\left|\frac{P_{v}}{Q_{v} p_{v}} Q_{v-1} \epsilon_{v}-\frac{P_{v-1}}{p_{v}} \epsilon_{v+1}\right|\right)^{\mu_{v}^{*}} \\
=\sum_{v=0}^{\infty} \frac{M^{-1 / \mu_{v}^{*}}}{\theta_{v}}\left(\frac{q_{v} P_{v}}{Q_{v} p_{v}}\left|\epsilon_{v}\right|+\left|\frac{P_{v}}{p_{v}} \Delta \epsilon_{v}-\frac{P_{v} q_{v}}{Q_{v} p_{v}} \epsilon_{v}+\epsilon_{v+1}\right|\right)^{\mu_{v}^{*}}<\infty .
\end{gathered}
$$

So, it can be seen immediately that the condition (6) is reduced to the condition (10) and the following condition:

$$
\sum_{v=0}^{\infty}\left(\frac{M^{-1}}{\theta_{v}^{1 / \mu_{v}^{*}}}\left|\frac{P_{v}}{p_{v}} \Delta \epsilon_{v}-\frac{P_{v} q_{v}}{Q_{v} p_{v}} \epsilon_{v}+\epsilon_{v+1}\right|\right)^{\mu_{v}^{*}}<\infty .
$$

Since $\mu_{v}^{*}>1$ for all $v$, it can be written that

$$
\begin{aligned}
\left(M^{-1} \theta_{v}^{-1 / \mu_{v}^{*}}\left|\frac{P_{v}}{p_{v}} \Delta \epsilon_{v}+\epsilon_{v+1}\right|\right)^{\mu_{v}^{*}} & =\left(\frac{M^{-1}}{\theta_{v}^{1 / \mu_{v}^{*}}}\left|\frac{P_{v}}{p_{v}} \Delta \epsilon_{v}-\frac{P_{v} q_{v}}{Q_{v} p_{v}} \epsilon_{v}+\frac{P_{v} q_{v}}{Q_{v} p_{v}} \epsilon_{v}+\epsilon_{v+1}\right|\right)^{\mu_{v}^{*}} \\
& \leq 2^{H-1}\left\{\left(\frac{M^{-1}}{\theta_{v}^{1 / \mu_{v}^{*}}}\left|\frac{P_{v}}{p_{v}} \Delta \epsilon_{v}-\frac{P_{v} q_{v}}{Q_{v} p_{v}} \epsilon_{v}+\epsilon_{v+1}\right|\right)^{\mu_{v}^{*}}\right. \\
& \left.+\left(\frac{M^{-1}}{\theta_{v}^{1 / \mu_{v}^{*}}}\left|\frac{P_{v} q_{v}}{Q_{v} p_{v}} \epsilon_{v}\right|\right)^{\mu_{v}^{*}}\right\}
\end{aligned}
$$

where $H=\sup \left\{\mu_{v}^{*}\right\}$. So, it can be obtained that

$$
\sum_{v}^{\infty}\left(\frac{M^{-1}}{\theta_{v}^{1 / \mu_{v}^{*}}}\left|\frac{P_{v}}{p_{v}} \Delta \epsilon_{v}+\epsilon_{v+1}\right|\right)^{\mu_{v}^{*}}<\infty
$$

which completes proof. 
Theorem 3.2 Let $\left(\theta_{n}\right)$ and $\left(\psi_{n}\right)$ be any sequences of positive numbers. If $\left(\mu_{n}\right)$ and $\left(\lambda_{n}\right)$ are any bounded sequences of positive numbers such that $\mu_{n} \leq 1$ and $\lambda_{n} \geq 1$ for all $n$, then $\epsilon \in$ $\left(\left|\bar{N}, p_{n}, \theta\right|(\mu),\left|\bar{N}, q_{n}, \varphi\right|(\lambda)\right)$ if and only if

$$
\begin{gathered}
\sup _{v}\left|\psi_{n}^{1 / \lambda_{n}^{*}} M^{-1 / \mu_{v}} \theta_{v}^{-1 / \mu_{v}^{*}} \frac{P_{v} q_{v}}{Q_{v} p_{v}} \epsilon_{v}\right|^{\lambda_{n}}<\infty \\
\sup _{v} \sum_{n=v+1}^{\infty}\left|\psi_{n}^{1 / \lambda_{n}^{*}} M^{-1 / \mu_{v}} \theta_{v}^{-1 / \mu_{v}^{*}} \frac{q_{n}}{Q_{n} Q_{n-1}}\left(\frac{Q_{v-1} P_{v}}{p_{v}} \epsilon_{v}-\frac{Q_{v} P_{v-1}}{p_{v}} \epsilon_{v+1}\right)\right|^{\lambda_{n}}<\infty
\end{gathered}
$$

Proof. If we take the diagonal matrix $W$ instead of $A$ in Theorem 2.4, then (7) and (8) are directly satisfied. Moreover, the condition (9) can be written as

$$
\sup _{v}\left\{\mid \frac{\psi_{v}^{1 / \lambda_{v}^{*}}}{\left.\left.M^{1 / \mu_{v} \theta_{v}^{1 / \mu_{v}^{*}}} \frac{q_{v} P_{v}}{Q_{v} p_{v}} \epsilon_{v}\right|^{\lambda_{v}}+\sum_{n=v+1}^{\infty}\left|\frac{\psi_{n}^{1 / \lambda_{n}^{*}}}{M^{1 / \mu_{v}} \theta_{v}^{1 / \mu_{v}^{*}}} \frac{q_{n}}{Q_{n} Q_{n-1}}\left(\frac{Q_{v-1} P_{v}}{p_{v}} \epsilon_{v}-\frac{Q_{v} P_{v-1}}{p_{v}} \epsilon_{v+1}\right)\right|^{\lambda_{n}}\right\}}\right\}
$$

So, this completes the proof.

Corollary 3.3 Assume that $\left(\theta_{n}\right)$ and $\left(\psi_{n}\right)$ are any sequences of positive numbers and $k \geq 1$. Then, necessary and sufficient conditions for $\epsilon \in\left(\left|\bar{N}, p_{n}, \theta\right|,\left|\bar{N}, q_{n}, \psi\right|_{k}\right)$ are

$$
\begin{gathered}
\sup _{v}\left|\psi_{v}^{1 / k^{*}} \frac{P_{v} q_{v}}{Q_{v} p_{v}} \epsilon_{v}\right|^{k}<\infty, \\
\sup _{v} \sum_{n=v+1}^{\infty}\left|\psi_{n}^{1 / k^{*}} \frac{q_{n}}{Q_{n} Q_{n-1}}\left(\frac{Q_{v-1} P_{v}}{p_{v}} \epsilon_{v}-\frac{Q_{v} P_{v-1}}{p_{v}} \epsilon_{v+1}\right)\right|^{k}<\infty .
\end{gathered}
$$

Corollary 3.4 Let $\left(\theta_{n}\right)$ be any sequences of positive numbers and $k>1$. Then, $\epsilon \in$ $\left(\left|\bar{N}, p_{n}, \theta\right|_{k},\left|\bar{N}, q_{n}\right|\right)$ if and only if

$$
\begin{gathered}
\sum_{v}^{\infty}\left(\frac{P_{v} q_{v}}{Q_{v} p_{v}} \theta_{v}^{-1 / k^{*}}\left|\epsilon_{v}\right|\right)^{k^{*}}<\infty \\
\sum_{v}^{\infty}\left(\theta_{v}^{-1 / k^{*}}\left|\frac{P_{v}}{p_{v}} \Delta \epsilon_{v}+\epsilon_{v+1}\right|\right)^{k^{*}}<\infty .
\end{gathered}
$$

Following two theorems have been given by (Sarıöl and Orhan, 1995).

Corollary 3.5 Let $1 \leq k<\infty$. Then, necessary and sufficient conditions for $\epsilon \in$ $\left(\left|\bar{N}, p_{n}\right|,\left|\bar{N}, q_{n}\right|_{k}\right)$ are

$$
\begin{array}{ll}
\text { a. } & \epsilon_{n}=O(1) \\
\text { b. } & \Delta \epsilon_{n}=O\left(p_{n} / P_{n}\right) \\
\text { c. } & \epsilon_{n}=O\left(\left(p_{n} / P_{n}\right)\left(Q_{n} / q_{n}\right)^{1 / k}\right)
\end{array}
$$

as $n \rightarrow \infty$, where $\Delta \epsilon_{n}=\epsilon_{n}-\epsilon_{n+1}$.

Proof. In Theorem 3.2, we take $\mu_{v}=1, \theta_{v}=\frac{P_{v}}{p_{v}}, \lambda_{v}=k \geq 1$ and $\psi_{n}=\frac{Q_{v}}{q_{v}}$ for all $v$. Then, the condition (12) is reduced to (c). By Lemma 2.2, (13) can be arranged as

$$
\frac{P_{v}}{p_{v}} \Delta \epsilon_{v}-\frac{P_{v} q_{v}}{Q_{v} p_{v}} \epsilon_{v}+\epsilon_{v+1}=O(1)
$$


Moreover, since $\frac{P_{v} q_{v}}{Q_{v} p_{v}} \epsilon_{v}=O\left(\left(\frac{q_{v}}{Q_{v}}\right)^{1 / k^{*}}\right)=O(1)$, the last condition is equivalent to

which completes the proof.

$$
\frac{P_{v}}{p_{v}} \Delta \epsilon_{v}+\epsilon_{v+1}=O(1)
$$

Corollary 3.6 Let $1<k<\infty$. Then, $\epsilon \in\left(\left|\bar{N}, p_{n}\right|_{k},\left|\bar{N}, q_{n}\right|\right)$ if and only if
a. $\quad \sum_{v=1}^{\infty}\left(p_{v} / P_{v}\right)\left|\frac{P_{v}}{p_{v}} \Delta \epsilon_{v}+\epsilon_{v+1}\right|^{k^{*}}<\infty$,
b. $\sum_{v=1}^{\infty}\left(p_{v} / P_{v}\right)\left(\frac{P_{v} q_{v}}{Q_{v} p_{v}}\left|\epsilon_{v}\right|\right)^{k^{*}}<\infty$

where $1 / k+1 / k^{*}=1$ for $k>1$.

Proof. If we take $\mu_{v}=k, \theta_{v}=\frac{P_{v}}{p_{v}}$ for all $v$ in Theorem 3.1, the conditions (10) and (11) are reduced to (a) and (b).

Corollary 3.7 $\epsilon \in\left(\left|\bar{N}, p_{n}\right|,\left|\bar{N}, q_{n}\right|\right)$ if and only if
a. $\epsilon_{n}=O(1)$
b. $\Delta \epsilon_{v}=O\left(p_{n} / P_{n}\right)$
c. $\epsilon_{n}=O\left(p_{n} Q_{n} / P_{n} q_{n}\right)$ as $n \rightarrow \infty$.

\section{CONCLUSION}

Let $\left(\theta_{n}\right),\left(\psi_{n}\right)$ be sequences of positive numbers and $\left(\mu_{n}\right),\left(\lambda_{n}\right)$ be any bounded sequences of positive numbers. In this study, applying the main theorems in (Gökçe and Sarıgöl, 2018) to summability factors, we obtain the characterizations of the sets $\left(\left|\bar{N}, p_{n}, \theta\right|(\mu),\left|\bar{N}, q_{n}\right|\right) \quad$ and $\left(\left|\bar{N}, p_{n}, \theta\right|(\mu),\left|\bar{N}, q_{n}, \psi\right|(\lambda)\right)$. Also, in the special case, we get some well-known results.

\section{REFERENCES}

Gökçe F, Sarı̈öl M A, 2018. A new series space $\left|\bar{N}_{P}^{\theta}\right|(\mu)$ and matrix transformations with applications. Kuwait Journal of Science, 45(4): 1-8.

Grosse-Erdmann KG, 1993. Matrix transformations between the sequence spaces of Maddox. Journal of Mathematical Analysis and Applications, 180(1): 223-238.

Mitrinovic DS, 1970. Analytic Inequalties. Springer-Verlag, Berlin.

Orhan C, Sarıgöl MA, 1993. On absolute weighted mean summability. The Rocky Mountain Journal of Mathematics, 23(3): 1091-1097.

Sarıgöl MA, 2016. Norms and compactness of operators on absolute weighted mean summable series. Kuwait Journal of Science, 43(4): 68-74.

Sarıgöl MA, 2013. An inequality for matrix operators and its applications. Journal of Classical Analysis, 2(2): 145-150.

Sarıgöl MA, 2011. Matrix transformatins on fields of absolute weighted mean summability. Studia Scientiarum Mathematicarum Hungarica, 48(3): 331341.

Sarıgöl MA, Bor H, 1995. Characterization of absolute summability factors. Journal of Mathematical Analysis and Applications, 195 (2): 537-545. 